\title{
Knowledge, attitudes and practice of breast sonography among females at a rural health facility in Uganda
}

Aloysius Gonzaga Mubuuke

Keywords: global health

https://doi.org/10.29392/joghr.3.e2019024

\section{Journal of Global Health Reports}

Vol. 3, 2019

\section{Introduction}

Breast sonography has become an important evaluation tool in assessing breast masses and other suspicious breast changes. Despite its importance and popularity in many large hospitals, breast sonography remains under-utilized in many rural health facilities.

\section{Objective}

The purpose of this study was to explore the knowledge, attitudes and practice of breast sonography amongst a group women in a rural health context.

\begin{abstract}
Methods
It was a cross-sectional study in which data from women was collected using interviewer-administered questionnaires. The qualitative component of the data was analysed using thematic analysis. For the quantitative component, SPSS was used for analysis. Association between socio-demographic characteristics and adequacy of knowledge, attitudes and practice of breast sonography were determined using both bivariate and logistic regression analysis. A Chi-square was used to test statistical significance.
\end{abstract}

\section{Results \\ Majority (95\%) of the women in this study lacked knowledge of breast sonography, and generally all the women demonstrated a negative attitude towards breast sonography. Knowledge about breast sonography as well as recommendation by a health worker remained the only significant factors that seemed to influence the practice of seeking for breast sonography services.}

\section{Conclusions}

The women in this study demonstrated limited knowledge of breast sonography which perhaps contributed to the negative attitude and poor practice of seeking breast sonography services at the health facility.

Breast cancer is the third commonest cancer in women in Uganda following Kaposi sarcoma and cervical cancer. ${ }^{1}$ A previous study conducted in Uganda reported breast cancer incidence at 22: 100,000 with a five year survival rate of $56 \% .^{2}$ Breast cancer has also been reported as being one of the most frequent cancers of women in other areas. ${ }^{3}$ It has been reported that by the year 2020, almost $70 \%$ of new cancer cases will occur within people from less developed countries, with majority of these cancers likely to be breast cancers. ${ }^{4}$ Literature has shown that this is likely due to late presentation amongst women especially from low-income countries where there are no formal breast cancer screening programmes, hence having little survival probabilities.., 6 The increased breast cancer rates in developing countries could also be attributable to the adoption of western life styles and diet. ${ }^{1}$ In addition, there is limited knowledge and poor attitude in relation to breast cancer issues. Knowl- edge on breast cancer and attitude have been reported to be important in determining the stage at which women present to health facilities. ${ }^{7}$ It has also been reported that factors relating to women's knowledge and beliefs about breast cancer can perhaps contribute to more positive health seeking behaviours. ${ }^{8,9}$ Early detection of breast cancer through regular and routine screening remains one of the most significant steps in increasing survival rates. ${ }^{10}$ This is likely to result into prompt management and treatment, and thus better patient outcomes. ${ }^{11}$

Some studies on knowledge, attitude and practices on breast cancer have been conducted in Africa. ${ }^{5,12}$ However, these studies have either specifically explored the subject of women knowledge and attitude on issues of breast cancer broadly or on mammography as a screening modality. In addition, these studies have largely been conducted in large urban hospitals where arguably, women are more educated 
and thus are likely to be more informed. Mammography remains expensive to majority of women in developing countries and most especially in the rural settings. Besides, most resource-constrained countries do not have formalized mammography screening programmes in the health care system, leaving only those few women who can afford the cost to access mammography services for purposes of breast cancer screening.

Though not advocated for to be used as a screening tool, breast ultrasound can still play a vital role in the early evaluation of breast masses. ${ }^{13,14}$ Unlike mammography, sonography services are currently widely available in many rural settings and relatively affordable to most women. Therefore, breast sonography could perhaps be a valuable initial tool in the evaluation of palpable and non-palpable breast masses, especially in rural health facilities where mammography services are not readily available. Using breast sonography, breast masses and other suspicious breast changes can be identified early enough, characterized and further investigations recommended.

In Uganda where this study was conducted from, sonography equipment is now present in most health facilities including both urban and rural health facilities. This was done as a way of bringing sonography services closer to the people in rural settings. However, despite the fact that sonography services are widely available in most rural health facilities in Uganda, women referred from rural health settings to secondary and tertiary hospitals still present late with advanced breast cancer. In many cases, the women are referred when the breast cancer has already spread to other body organs and when effective management is almost impossible.

There has been a dearth of published literature especially from the context of a rural setting exploring the knowledge, attitudes and practice of women regarding the use of breast sonography especially in the evaluation of breast masses and other suspicious breast changes. This study set out to explore the knowledge, attitudes and practice of women in a rural setting towards the use of breast sonography. Hopefully, findings from the study will raise awareness regarding the role of breast sonography as a starting point in the evaluation breast masses especially in rural settings where sonography services are readily available.

\section{METHODS}

\section{SITE}

This study was conducted at a rural hospital located in central Uganda, about $120 \mathrm{Km}$ from the capital city. It is a mission hospital that receives patients from many of the surrounding smaller health centres.

\section{STUDY DESIGN}

The study was cross-sectional in nature in which interviewer-administered questionnaires were used to collect data from adult women (i.e. 18 years and above). Data was collected for 8 weeks between June and August 2017. The questionnaire had both quantitative and qualitative components. The questionnaires were administered in both English and Luganda (a local language). The questions asked rotated around key issues such as whether the women knew about breast sonography, uses of breast sonography, when it is recommended to do it, source of knowledge of breast sonography, their opinions towards doing breast sonography and how often and under what circumstances they did breast sonography. Correct and consistent responses relating to the value and importance of breast sonography were taken as adequate knowledge. Attitude was considered optimal if the responses from the women reflected positivity about breast sonography, and practice was considered satisfactory if the women responded correctly to questions regarding use of breast sonography and showing desire to do it. Socio-demographic data of the women was also collected. All adult women were eligible to participate in the study regardless of whether they had had a breast ultrasound examination prior to the study period. The interview questions were first piloted with two women prior to commencing the study to assess their validity.

\section{SAMPLING STRATEGY}

Consecutive sampling was used to recruit 100 women into the study. This strategy was the most appropriate for the study as it would avail every available adult woman a chance to participate.

\section{DATA ANALYSIS}

Thematic analysis was used for the qualitative component of the study. This type of analysis has been reported to be very useful in studies of a qualitative nature. ${ }^{15}$ The audiorecorded interview responses were transcribed. The transcriptions became the raw data. This raw data was proofread against the recorded interviews to ensure accuracy and contextual quotations were used when reporting the qualitative findings. The quantitative data went through cleanliness and consistency tests, frequency analysis and entered into SPSS version 10.0 statistical program. Age of participants was expressed as means of \pm standard deviation (SD). Associations between socio-demographic characteristics and adequacy of KAP of breast sonography were determined using both bivariate and logistic regression analysis. A Chisquare was used to test statistical significance and a $P$-value of 0.05 was adopted for the study.

\section{ETHICAL CONSIDERATIONS}

Permission to conduct the study was granted by the hospital administration and School of Medicine Ethics Committee, Makerere University. Each interview commenced with obtaining consent from each participant, explanation of the study followed by a discussion of any concerns. Participants were assured of the confidentiality of their opinions. The tape-recorded interview followed the completion of the aforementioned tasks. Confidentiality, autonomy and dignity of all the women was strictly observed throughout the study. In addition, the women were assured of their right to decline participating in the study and also not to answer questions they felt uncomfortable with. The women were also assured that there will be no harm, prejudice, malice or any form of danger should they wish not to participate 
Table 1. Socio-demographic characteristics of the women

\begin{tabular}{lc}
\hline Characteristic & No. (\%) \\
\hline Age (years, mean \pm SD) & $21(21 \%)$ \\
$20-29(22.8 \pm 2.4)$ & $27(27 \%)$ \\
$30-39(37.2 \pm 2.0)$ & $43(43 \%)$ \\
$40-49(43.8 \pm 2.4)$ & $2(2 \%)$ \\
$50-59(52.4 \pm 4.4)$ & $5(5 \%)$ \\
$60-69(64.1 \pm 3.0)$ & $2(2 \%)$ \\
$70-79(72.5 \pm 4.3)$ & \\
Level of education: & $0(0 \%)$ \\
Tertiary & $20(20 \%)$ \\
Secondary & $60(60 \%)$ \\
Primary & $20(20 \%)$ \\
Never went to school & \\
Employment: & $43(43 \%)$ \\
Employed & $57(57 \%)$ \\
Unemployed & \\
Marital status: & $5(5 \%)$ \\
Married & $80(80 \%)$ \\
Co-habiting & $15(15 \%)$ \\
Single &
\end{tabular}

in the study. This study also followed the principles of the Helsinki Declaration.

\section{RESULTS}

\section{SOCIO-DEMOGRAPHIC INFORMATION}

One hundred women were interviewed in this study. The socio-demographic characteristics of the women are summarized in Table 1.

From Table 1, the majority of the women who participated in the study were below 50 years of age and hence in the reproductive age. Majority had only basic level education.

\section{KNOWLEDGE}

The level of knowledge of the women about breast sonography is summarized in Table 2 .

The most significant feature from Table 2 , is that whereas it can be seen that all the women who participated in this study had an idea about sonography in general terms, almost all of them (95\%) did not know specifically breast sonography, hence it can be concluded that almost all the women at this rural health facility who participated in the study did not know about breast sonography. The general knowledge about sonography was mainly received from the health facility, radios and health promotion campaigns carried out by the health facility staff.

\section{ATTITUDES}

The women`s attitude towards breast sonography generally reflected negativity even after explaining to them what breast sonography is all about. The following responses were key in capturing this observation:

"I do not know what examination you are talking about. Scan is only used to check my baby and not my other private parts..... cannot do it”, one woman commented.

"Ka T.V ako nkamanyi, naye batugamba nti kakebera bakazi bambuto so si mabeere", another women retorted, literally meaning that, "I know about ultrasound, but we were told that it is only useful for pregnant women and not to check our breasts".

One lady who had some knowledge about sonography from a friend said:

"I was told that I need to go for scan when am pregnant and not to check my breasts...I can always check my breasts or ask my husband to do it..... do I need to go into that scan....no, no, no".

Another woman weighed in: "The T.V only checks babies in my stomach. When you talk about checking my breasts in the T.V, I do not understand".

"I cannot expose my breasts in the scan T.V....the doctor can check me and see if my breasts are sick", another woman responded.

Some of the women said that they were told that they should check their breasts at home monthly and also go for check up with the doctor once in a while, but breast ultrasound was not mentioned. This is reflected in the response below:

"I was told to check my breasts every month by the doctor, so no need to expose my private breasts in the T.V".

\section{PRACTICES}

$40 \%(n=40)$ of the women in this study had previously undergone some form of sonographic examination, though not specifically breast sonography. Only $5 \%(n=5)$ had ever undergone breast sonography examination. Some key factors seemed to influence the practice of seeking for breast sonography services. For example, with regard to seeking breast sonography services, level of education, marital status, employment, having knowledge and recommendation by a health worker were significant on bivariate analysis $(P=0.004)$. However, only knowledge about breast sonography and recommendation by a health worker remained the only significant variables on logistic regression analysis $(P=0.002)$. Women who had some knowledge of breast sonography were about four times more likely to go for it than women without knowledge (odds ratio $(\mathrm{OR})=3.78$, 95\% confidence interval $(\mathrm{CI})=1.50-9.42)$. Women with a recommendation from a health worker to do breast sonography were nearly seven times more likely to go for breast sonography compared to women without a health worker's recommendation ( $\mathrm{OR}=6.8)$. The barrier to go for breast sonography expressed by almost all the women was a lack of knowledge of what this investigation is all about and what it is intended to do as well as having no requests from the health workers to carry out the investigation. Most of the women in this study had undergone an ultrasound exami- 
Table 2. Knowledge about breast sonography

\begin{tabular}{|c|c|}
\hline Item & $\begin{array}{l}\text { No. correct } \\
\text { responses (\%) }\end{array}$ \\
\hline \multicolumn{2}{|c|}{ Knowledge about breast sonography: } \\
\hline More than optimal knowledge & $0(0 \%)$ \\
\hline Optimal knowledge & $0(0 \%)$ \\
\hline Partially optimal knowledge & $5(5 \%)$ \\
\hline No idea about breast sonography & $95(95 \%)$ \\
\hline \multicolumn{2}{|l|}{$\begin{array}{l}\text { What type of energy is used during } \\
\text { breast sonography? }\end{array}$} \\
\hline X-rays & $0(0 \%)$ \\
\hline Sound & $0(0 \%)$ \\
\hline Do not know & $100(100 \%)$ \\
\hline \multicolumn{2}{|l|}{$\begin{array}{l}\text { Is there risk of breast cancer after } \\
\text { using sonography? }\end{array}$} \\
\hline Yes & $0(0 \%)$ \\
\hline No & $0(0 \%)$ \\
\hline Do not know & $100(100 \%)$ \\
\hline \multicolumn{2}{|l|}{$\begin{array}{l}\text { Have heard about ultrasound } \\
\text { generally? }\end{array}$} \\
\hline Yes & $100(100 \%)$ \\
\hline No & $0(0 \%)$ \\
\hline \multicolumn{2}{|l|}{$\begin{array}{l}\text { Source of information regarding } \\
\text { ultrasound: }\end{array}$} \\
\hline Health facility & $50(50 \%)$ \\
\hline From friends & $10(10 \%)$ \\
\hline Radio & $20(20 \%)$ \\
\hline Television & $5(5 \%)$ \\
\hline Health promotion campaigns & $15(15 \%)$ \\
\hline \multicolumn{2}{|l|}{$\begin{array}{l}\text { Have you specifically heard about } \\
\text { breast ultrasound? }\end{array}$} \\
\hline Yes & $5(5 \%)$ \\
\hline No & 95 (95\%) \\
\hline
\end{tabular}

nation, most notably during their pregnancy, but not breast ultrasound.

\section{DISCUSSION}

\section{KNOWLEDGE}

This study was conducted with women at a rural health facility with an aim of assessing their knowledge, attitude and practices regarding breast sonography. Findings from the study have demonstrated that nearly all the women who participated had no knowledge of breast sonography, although this health facility had an ultrasound machine and also regularly carried out health promotion activities in the surrounding communities. This lack of knowledge probably contributed to the women`s negative attitude towards doing breast sonography as well as the poor practice of not seeking for breast sonography services. However, it should be noted that majority of the women generally had some idea about ultrasound, though not specifically breast ultrasound. The possible explanation for this is the routine use of ultrasound in mainly obstetric conditions as part of the antenatal care for women. ${ }^{16}$ It has been reported in literature that the use of ultrasound as part of antenatal care for pregnant women has become routine practice even in rural settings where sonography equipment is relatively available. ${ }^{16}$ However, despite the availability of ultrasound equipment in many rural health facilities, the service has not been utilized to evaluate breast conditions in this era of increasing breast cancer cases. This study has confirmed that despite the presence of ultrasound equipment in this rural health facility, the women do not know and are thus not undergoing breast sonography, yet breast cancer cases from rural settings are referred very late when management is almost impossible.

The three methods recommended for detection of breast cancer are BSE, CBE by a health care professional, and mammography, the third being the most effective. ${ }^{17}$ It has also been recommended that between the ages of 40 and 49 years, women should undergo a CBE and mammography every year or 2 . Women older than 50 years should have an annual CBE as well as a mammogram. ${ }^{18}$ Whilst mammography remains the gold standard for breast cancer screening for all women, it is resource-intensive and expensive for many developing countries and most rural settings do not have mammography equipment. Although, a good number of women in this study seemed to be employed (43\%), these are informal small-scale jobs that just bring in money to cater for basic needs. Therefore, paying for mammography still remains unaffordable for many women. Besides, many young women below the age of 30 years are not recommended to do routine mammography.

In a rural context where mammography may not be readily accessible, breast sonography can play a vital initial role in the evaluation of breasts with suspicious features/masses and characterizing these masses. From ultrasound findings, further investigations such as mammography can then be recommended or just follow up at short intervals. Using breast sonography would also assist health workers in rural health care facilities to identify women who need immediate mammography services and hence referred to tertiary hospitals. However, the use of breast sonography as an initial evaluative tool appears to be hindered by a lack of knowledge from the women about its exact role. There is need to sensitize the women in this regard and hence increase the use of breast sonography especially in rural settings where ultrasound equipment is now relatively accessible.

\section{ATTITUDES}

The attitude of women in this study towards breast sonography was generally negative. One plausible explanation for this observation could be due to the limited knowledge regarding the value of breast sonography. From this study, it appears that the women were told about the use of ultrasound in obstetrics during antenatal care. However, they were not aware of it being applied for evaluation of breast symptoms. In one study done in an almost similar population in Uganda, women reported having a very positive attitude towards doing an obstetric ultrasound scan. ${ }^{16}$ The authors of this study reported that the idea of seeing their babies and knowing the fetal gender perhaps contributed to 
this positive attitude. In this present study, women reported a negative attitude towards breast sonography. Again, this points to an information gap amongst these women that could perhaps have contributed to the observed poor attitude of doing breast sonography. There is therefore need for health workers to sensitize the women about the value and importance of breast sonography especially in this era of increasing breast cancer. In situations where women are knowledgeable about the investigation, they may even make self-requests for ultrasound examinations such as obstetric scans. However, this may not be the case with specialized sonographic examinations such as breast sonography. The health workers need to promote the use of breast sonography especially in rural areas where sonography equipment is now readily accessible. This would perhaps assist women with suspicious breast findings to access further management.

\section{PRACTICE}

The practice of seeking for breast sonography services seemed to be influenced by mainly two factors namely: having knowledge about the value of breast sonography and being recommended by a health worker. It was clear from this study that knowledge regarding the value of breast sonography was limited and that health workers never recommended women to do it. These arguably might influenced the practice of seeking for it. It is not clear as to why the health workers never recommended breast sonography for any of the women that participated in this study. It is probable that may be there was no indication to do breast sonography at all. However, it is also likely that the health workers themselves did not know when to recommend for it. In Uganda, many women from rural settings present with suspicious breast masses at tertiary hospitals without any prior breast sonography results, meaning that breast ultrasound is perhaps not routinely done in these rural health facilities despite the equipment being available.

Therefore, it is important to understand reasons as to why breast sonography services are not routinely performed despite the presence of the equipment. Either, there are no skilled personnel to perform the breast sonography investigations in these rural health facilities or the health workers do not recommend for it. In one study on the accuracy of breast sonography in evaluating breast masses, it was reported that breast ultrasound is useful in differentiating cystic from solid masses and in characterizing breast masses. This aids in the most appropriate course of action. ${ }^{19}$ In the absence of mammography services in many rural health settings, there is need to promote the use of breast sonography as an initial evaluative tool of breast masses and other breast changes. This will hopefully assist in identifying those women that need urgent attention such as immediate referral to tertiary hospitals before a breast cancer can spread to other areas. In addition, the use of breast sonography perhaps needs to be promoted in SubSaharan Africa and other resource-limited settings because of its wide availability, non-reliance on the use of ionizing radiation and its superiority in examining dense breasts for which mammography becomes less sensitive. ${ }^{10}$
This study has thus demonstrated that there is a significant knowledge gap regarding the value of breast sonography amongst women in this rural community. Although, not certain, this could arguably be the same trend in many other rural settings. This knowledge gap may have contributed to the poor attitude of women towards breast sonography and subsequently the poor practice of not seeking for breast ultrasound services. In rural settings where there is no mammography at all, breast sonography needs to be promoted as an initial tool to evaluate breast masses before referral for mammography or even biopsy in tertiary hospitals. The emphasis that has been put on the value of obstetric sonography in antenatal care needs to be put on the value of breast sonography in breast cancer investigations as well. This is particularly true for rural health facilities where sonography equipment is relatively accessible as compared to mammography. This study was however conducted in only one rural setting and may not necessarily represent the views from other rural health facilities, a major limitation. However, going forward, more empirical research is recommended in other rural settings. There is also need to explore from the health workers in the rural health facilities the possible reasons as to why breast sonography investigations are not routinely requested as compared to obstetric sonography for example.

\section{CONCLUSION}

Despite the value of breast sonography especially in the investigation of breast masses, women in this study generally had limited knowledge of this service. The limited knowledge of breast sonography most likely contributed to the negative attitude and subsequently the poor practice of seeking for it. It is recommended that the use of breast sonography needs to be promoted as an initial evaluative tool especially in rural health settings where mammography may not readily be accessible.

\section{ACKNOWLEDGEMENTS}

The author appreciates the hospital administration and the women who participated in the study.

\section{ETHICS APPROVAL AND CONSENT TO PARTICIPATE}

Ethics approval and consent to participate was obtained from the Research Ethics Committee, School of Medicine, Makerere University and the hospital administration.

\section{FUNDING}

None.

\section{COMPETING INTERESTS}

The author completed the Unified Competing interests form at http://www.icmje.org/coi_disclosure.pdf, and declares no conflicts of interest. 


\section{CORRESPONDENCE TO:}

Dr. Aloysius Gonzaga Mubuuke Department of Radiology

\section{School of Medicine}

College of Health Sciences

Makerere University
P.O. Box 7072

Kampala

Uganda

gmubuuke@gmail.com 


\section{REFERENCES}

1. Wabinga HR, Parkin DM, Wabwire-Mangeni F, Namboze S. Trends in cancer incidence in Kyadondo County, Uganda. Br J Cancer. 2000;82:1585-192.

2. Gakwaya A, Galukande M, Luwaga A, Jombwe J, Faulal J, Kiguli-Malwadde E, et al. Breast cancer guidelines for Uganda, 2nd Edition. African Health Sciences. 2008;8:126-132.

3. Dibble SL, Vanoni JM, Miaskowski C. Women's attitudes toward breast cancer screening procedures: Differences by ethnicity. Women's Health Issues. 1997;7(1):47-54. doi:10.1016/s1049-3867(96)00048-5

4. Gakwaya A, Kigula-Mugambe JB, Kavuma A, et al. Cancer of the breast: 5 -year survival in a tertiary hospital in Uganda. Br J Cancer. 2008;99(1):63-67. do i:10.1038/sj.bjc.6604435

5. Odusanya OO, Tayo OO. Breast cancer knowledge, attitudes and practice among nurses in Lagos, Nigeria. Acta Oncol. 2001;40(7):844-848. doi:10.1080/ $\underline{02841860152703472}$

6. Sadler GR, Dhanjal SK, Shah NB, et al. Asian Indian women: Knowledge, attitudes and behaviour toward breast cancer early detection. Public Health Nurs. 2001;18(5):357-363. doi:10.1046/j.1525-1446.2001.00 357.X

7. Cody HS III, Van Zee KJ. Re-excision-the other breast cancer epidemic. $N$ Engl J Med.

2015;373(6):568-569. doi:10.1056/nejme1507190

8. The Independent UK Panel on Breast-cancer Screening. The benefits and harms of breast-cancer screening: an independent review. Lancet. 2012;380:1778-186. doi:10.1016/S0140-6736(12)6161 1-023117178

9. Tabár L, Yen AMF, Wu WYY, et al. Insights from the breast cancer screening trials: how screening affects the natural history of breast cancer and implications for evaluating service screening programs. Breast $J$. 2014;21(1):13-20. doi:10.1111/tbj.12354

10. Riedl CC, Luft N, Bernhart C, et al. Triplemodality screening trial for familial breast cancer underlines the importance of magnetic resonance imaging and questions the role of mammography and ultrasound regardless of patient mutation status, age, and breast density. J Clin Oncol.

2015;33(10):1128-1135. doi:10.1200/jco.2014.56.8626
11. Puliti D, Duffy SW, Miccinesi G, et al. Overdiagnosis in mammographic screening for breast cancer in Europe: a literature review. J Med Screen. 2012;19(1_suppl):42-56. doi:10.1258/jms.2012.01208 $\underline{2}$

12. Elsie KM, Mubuuke AG, Businge F, Kawooya MG, Nakatudde R, Byanyima R. Current knowledge, attitudes and practices of women on breast cancer and mammography at Mulago Hospital. Pan Afr Med J. 2010;5:9. doi:10.4314/pamj.v5i1.56186

13. Berg WA, Zhang Z, Lehrer D. Detection of breast cancer with addition of annual screening ultrasound or a single screening MRI to mammography in women with elevated breast cancer risk. JAMA.

2012;307(13):1394-1404. doi:10.1001/jama.2012.388

14. Kuhl CK, Schrading S, Leutner CC, et al.

Mammography, breast ultrasound, and magnetic resonance imaging for surveillance of women at high familial risk for breast cancer. J Clin Oncol. 2005;23(33):8469-8476. doi:10.1200/jco.2004.00.4960

15. Braun V, Clarke V, Terry G. Thematic analysis. In: Rohleder P, Lyons A, eds. Qualitative Research in Clinical and Health Psychology. Palgrave MacMillan; 2014.

16. Mubuuke AG, Kiguli-Malwadde E, Businge F, Byanyima KR. Utilisation of obstetric sonography at a peri-urban health centre. Pan Afr Med J. 2010;7:24.

17. Ahmed F, Mahmud S, Hatcher J, Khan SM. Breast cancer risk factor knowledge among nurses in teaching hospitals of Karachi, Pakistan: A crosssectional study. BMC Nurs. 2006;5:6. doi:10.1186/147 2-6955-5-6

18. Okobia MN, Bunker CH, Okonofua FE, Osime U. Knowledge, attitude and practice of Nigerian women towards breast cancer: a cross-sectional study. World J Surg Oncol. 2006;4(1):11. doi:10.1186/1477-781 $\underline{9-4-11}$

19. Mubuuke AG. How accurate is ultrasound in evaluating palpable breast masses? Pan Afr Med J. 2010;7:1. doi:10.4314/pamj.v7i1.69094 